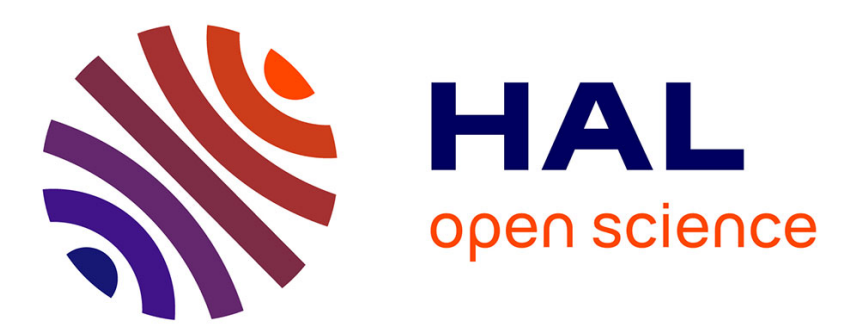

\title{
Tensile and flexural ultimate strength of fiber-reinforced ceramic-matrix composites
}

François Hild, Jean-Marc Domergue, Frederick A. Leckie, Anthony G. Evans

\section{To cite this version:}

François Hild, Jean-Marc Domergue, Frederick A. Leckie, Anthony G. Evans. Tensile and flexural ultimate strength of fiber-reinforced ceramic-matrix composites. International Journal of Solids and Structures, 1994, 31 (7), pp.1035 - 1045. 10.1016/0020-7683(94)90010-8 . hal-01636223

\section{HAL Id: hal-01636223 \\ https://hal.science/hal-01636223}

Submitted on 31 Oct 2019

HAL is a multi-disciplinary open access archive for the deposit and dissemination of scientific research documents, whether they are published or not. The documents may come from teaching and research institutions in France or abroad, or from public or private research centers.
L'archive ouverte pluridisciplinaire HAL, est destinée au dépôt et à la diffusion de documents scientifiques de niveau recherche, publiés ou non, émanant des établissements d'enseignement et de recherche français ou étrangers, des laboratoires publics ou privés. 


\title{
TENSILE AND FLEXURAL ULTIMATE STRENGTH OF FIBER-REINFORCED CERAMIC-MATRIX COMPOSITES
}

\author{
Françors Hild, †§ Jean-Marc Domergue, $\$ \S \uparrow$ \\ Frederick A. LeCKIE† and ANTHONY G. EVANS \\ $\dagger$ Department of Mechanical and Environmental Engineering, and $\ddagger$ Materials \\ Department, College of Engineering, University of California, Santa Barbara, \\ CA 93106, U.S.A.
}

\begin{abstract}
A constitutive equation has been derived for fiber-reinforced ceramic-matrix composites, based on fiber breakage and distributed fiber pull-out. Length-dependent and length-independen regimes, governed by the size of the specimen, are differentiated. The constitutive equation is used to predict the ultimate strength of fiber-reinforced ceramic-matrix composites subjected to tensile and flexural loadings.
\end{abstract}

\section{INTRODUCTION}

The stress-strain behavior of ceramic-matrix composites (CMCs) is nonlinear, provided that the interfaces slide with low shear resistance, $\tau$ (Aveston et al., 1971; Cao et al., 1990a,b). The loading of such composites results in two independent damage mechanisms : fiber failure and matrix cracking. The latter results in a diminished secant modulus $E_{s}$, as well as a permanent strain, $\bar{\varepsilon}_{0}$ (Pryce and Smith, 1992; Beyerle et al., 1992). Furthermore, the fibers are subject to global load sharing, whereby the load transmitted from each failed fiber is shared equally among the intact fibers. Some aspects of the associated fiber failure stochastics have already been addressed (Curtin, 1991a,b; Phoenix, 1992). Two key parameters have been identified (Henstenburg and Phoenix, 1989; Curtin, 1991a): (a) a characteristic length

$$
\delta_{c}^{m+1}=L_{0}\left[S_{0} R / \tau\right]^{m}
$$

where $m$ is the shape parameter, $R$ is the fiber radius, $S_{0}$ is a stress scale parameter and $L_{0}$ a reference length; (b) a characteristic strength

$$
S_{c}=S_{0}\left[L_{0} \tau / R S_{0}\right]^{1 /(m+1)} .
$$

When the gage length, $L$, is large compared with $\delta_{c}$, the fibers are capable of multiple failures within the gage section. Consequently, the ultimate strength $S_{u}$ is predicted to be gage length independent, and given by (Curtin, 1991b)

$$
S_{u}=f S_{c} F(m)
$$

with

$$
F(m) \cong[2 /(m+2)]^{1 /(m+1)}[(m+1) /(m+2)]
$$

where $f$ is the fiber volume fraction along the loading direction. Deviation from eqn (3) would be expected both for short gage lengths, $L \leqslant \delta_{c}$, and when the stress on the composites is nonuniform. These effects are analyzed in this paper. For this purpose a constitutive law

§Also at Laboratoire de Mécanique et Technologie, E.N.S. Cachan, C.N.R.S., Université Paris 6, 61 avenue du Président Wilson, F-94235 Cachan Cedex, France.

I Also at S.E.P., Les 5 chemins, Le Haillan, F-33160 Saint Médand en Jalles, France. 
is derived. The analytic approach used to devise this law has the same fundamental features established by others (Curtin, 1991a,b; Phoenix, 1993). However, a new direction is considered in order to provide approximate formulae that facilitate analysis of composite failure subject to complex loading situations. The utility of the approximation is justified, both by comparison with experiment and with the calculations of Curtin (1991a,b).

\section{THE BASIC STOCHASTIC MODEL}

The tensile stress $\bar{\sigma}$ of a composite with a saturation density of matrix cracks is considered. The matrix crack spacing is $L_{m}$, within a unit cell of length $L_{R}$ (Fig. 1a). The length $L_{R}$ is the recovery length and refers to the longest fiber that can be pulled out and cause a reduction in the load-carrying capacity. At reference stress, $T$, the recovery length is

$$
L_{R}=R T / \tau,
$$

where the reference stress $T$ is the fiber stress in the plane of the matrix crack. Generally, $L_{m} \ll L_{R}$ and the stress field in intact fibers has the form illustrated in Fig. 1(b). Consequently, the local stress in the fiber in the region $0 \leqslant x \leqslant L_{m} / 2$ is (Cox, 1952; Kelly, 1973)

$$
\sigma_{f}(T, x)=T-2 \tau x / R .
$$

If the fibers exhibit a statistical variation of strength that obeys a two-parameter Weibull law (Weibull, 1939), then the probability that a fiber would break anywhere within the characteristic length $L_{R}$ at or below a reference stress $T$ is given by

$$
P_{F}(T)=1-\exp \left[-\left(\frac{1}{L_{0}}\right) \int_{-L_{R} / 2}^{L_{R} / 2}\left\{\frac{\sigma_{F}(T, x)}{S_{0}}\right\}^{m} \mathrm{~d} x\right]
$$

Consequently, from eqns (5) and (6),

a)

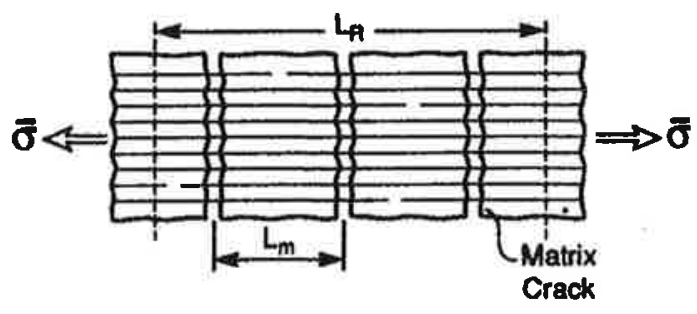

b)

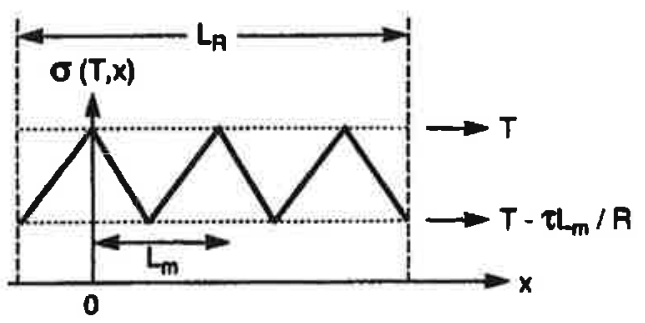

Fig. 1. (a) Diagram of the recovery length $L_{R}$ when the density of matrix cracks reaches saturation. (b) Fiber stress field $\sigma_{f}(T, x)$ along a length $L_{R}$ for a reference stress, $T$, when the fibers are intact. 


$$
P_{F}(T)=1-\exp \left[-\frac{L_{R}}{(m+1) L_{m}}\left(\frac{T}{S_{c}}\right)^{m+1}\left\{1-\left(1-\frac{\tau L_{m}}{R T}\right)^{m+1}\right\}\right]
$$

For most CMCs, $\tau L_{m} / R T \ll 1$, whereupon eqn (7) can be simplified to

$$
P_{F}(T) \cong 1-\exp \left[-\left(\frac{T}{S_{c}}\right)^{m+1}\right]
$$

The cumulative failure probability is thus independent of the total length of the composite.

The average stress $\tilde{\sigma}$ applied to the composite is related to the reference stress $T$ by

$$
\bar{\sigma}=f T\left[1-P_{F}(T)\right]+f \sigma_{p}(T),
$$

where $\sigma_{p}(T)$ denotes that component of the stress provided by failed fibers as they pull out from the matrix.

Various estimates may be used for the pull-out stress, $\sigma_{p}(T)$, as discussed in the Appendix. The preference is for a representation that can be used straightforwardly for further analysis, which also approximates the rigorous solutions. This is given by

$$
\sigma_{p}(T)=\frac{S_{c}}{2} \gamma\left[\frac{m+2}{m+1} ;\left(\frac{T}{S_{c}}\right)^{m+1}\right]
$$

where $\gamma\left[{ }^{\prime} ;\right]$ represents the incomplete gamma function. Then, the stress on the composite becomes

$$
\bar{\sigma}=f T\left[1-P_{\digamma}(T)\right]+\frac{f S_{c}}{2} \gamma\left[\frac{m+2}{m+1} ;\left(\frac{T}{S_{c}}\right)^{m+1}\right]
$$

If pull-out were neglected, the following formulae would apply

$$
\bar{\sigma}=f T\left[1-P_{F}(T)\right]
$$

and

$$
f T=\frac{\bar{\sigma}}{1-P_{F}(T)} .
$$

This latter expression is analogous to the concept of effective stress in the framework of continuum damage mechanics (Kachanov, 1958 ; Rabotnov, 1963 ; Lemaitre and Chaboche, 1985), when the damage variable is described as the percentage of broken fibers (Krajcinovic and Silva, 1982; Hult and Travnicek, 1983 ; Hild et al., 1992) in a cell of length $L_{R}$.

For the analysis of complex loadings, it is useful to relate the average stress $\tilde{\sigma}$ and strain $\bar{\varepsilon}$. This is obtained from eqn (11) by using, $\bar{\varepsilon} \cong T / E_{f}$, as

$$
\bar{\sigma}=f E_{f} \bar{\varepsilon}\left[1-P_{F}\left(E_{f} \bar{\varepsilon}\right)\right]+f \frac{S_{c}}{2} \gamma\left[\frac{m+2}{m+1} ;\left(\frac{E_{f} \bar{\varepsilon}}{S_{c}}\right)^{m+1}\right]
$$

or

$$
\bar{\sigma} / f S_{c}=\left(E_{f} \bar{\varepsilon} / S_{c}\right)\left[1+\sum_{n \geq 1} \frac{(-1)^{n}}{2 n !} \frac{2+n(m+1)}{1+n(m+1)}\left(E_{f} \bar{E} / S_{c}\right)^{n(m+1)}\right]
$$

where $E_{f}$ is Young's modulus for the fiber. In general, thermal residual stresses due to SAS 31:7-J 
processing cause an additional contribution to the strain associated with the displacements that arise upon matrix cracking (Pryce and Smith, 1992; Beyerle et al., 1992).

The ultimate tensile strength of the composite is defined by the condition

$$
\mathrm{d} \bar{\sigma} / \mathrm{d} \bar{\varepsilon}=0
$$

or

$$
\mathrm{d} \tilde{\sigma} / \mathrm{d} T=0 .
$$

This condition establishes that the ultimate strength arises when

$$
\frac{T}{S_{c}}=\left(\frac{2}{m+1}\right)^{1 /(m+1)}
$$

at a recovery length

$$
\frac{L_{R}}{\delta_{c}}=\left(\frac{2}{m+1}\right)^{1 /(m+1)}
$$

This function for $T / S_{c}$, at the ultimate, is identical to the one suggested by Phoenix (1993) based on a numerical study. Consequently, the ultimate tensile strength has the same form as eqn (3), but with

$$
F(m)=\left(\frac{2}{m+1}\right)^{1 /(m+1)}\left[1+\sum_{n \geqslant 1} \frac{(-1)^{n}}{n !}-\frac{2+n(m+1)}{1+n(m+1)} \frac{2^{n-1}}{(m+1)^{n}}\right] .
$$

This ultimate tensile strength is compared with other predictions (see the Appendix) in Fig. 2. The three curves, illustrate the effect of the different levels of approximation, upon using the same choice of $T$ at ultimate [eqn (16)]. The result presented in this paper is a lower bound, which neglects the exclusion zones, as well as the fiber breaks outside the recovery length. The result based on Curtin (1991b) neglects only the exclusion zones. The

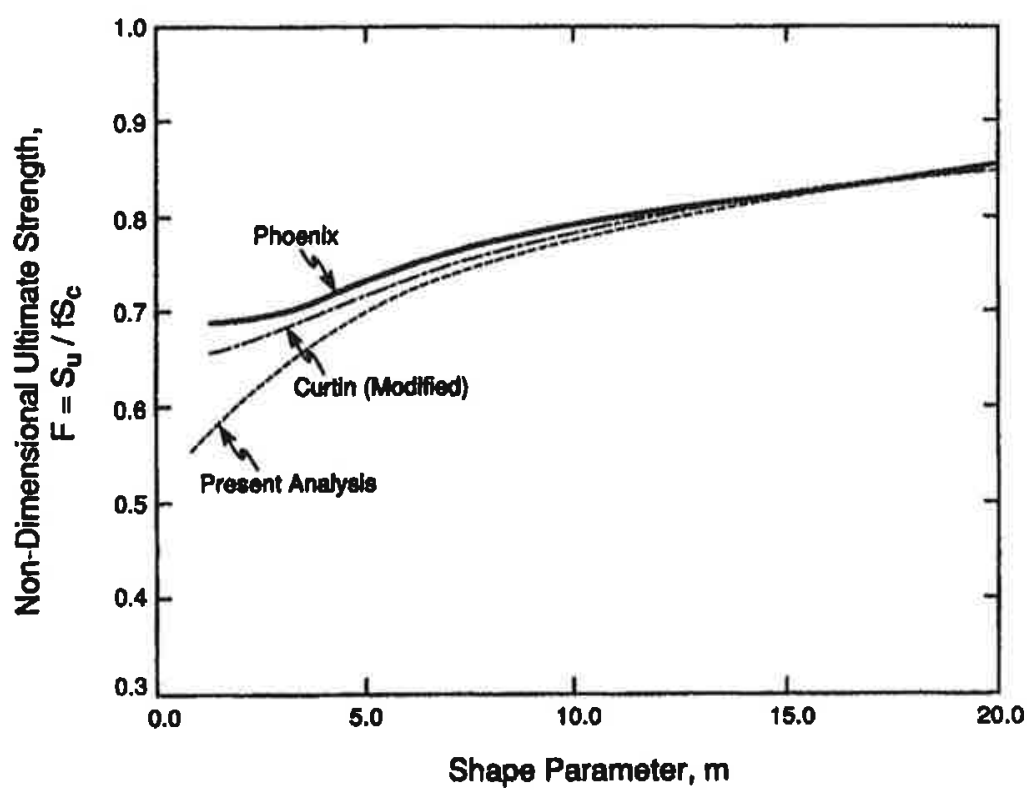

Fig. 2. Comparison between the lower bound ultimate tensile strength derived in this paper with two other predictions. The modified Curtin result neglects the exclusion zones. The Phoenix solution is rigorous. 
Phoenix (1993) result considers all three effects. It is apparent that, except at small $m$, the major contribution to the ultimate tensile strength comes from the fibers breaking inside the recovery length. Consequently, the present analytical result should provide useful lower bond extractions for new problems. The two problems to be addressed here are: (i) short specimens with $L \leqslant L_{R}$ and (ii) flexural loading.

\section{SHORT SPECIMENS}

When the recovery length $L_{R}$ becomes greater than the total length of the composite $L$, the previous results no longer apply, and the cumulative failure probability becomes length-dependent

$$
P_{F}(T) \cong 1-\exp \left[-\frac{L}{L_{0}}\left(\frac{T}{S_{0}}\right)^{m}\right]
$$

The external stress takes the form

$$
\bar{\sigma}=f T\left[1-P_{F}(T)\right]+\frac{f S_{c}}{2} \gamma\left[\frac{m+2}{m+1} ;\left(\frac{L}{\delta_{c}}\right)^{m+1}\right]+f \sigma_{p}^{*}(T),
$$

where the stress $\sigma_{p}^{*}$ corresponds to the revised contribution from pull-out

$$
\sigma_{p}^{*}(T)=\frac{\tau L}{2 R}\left\{\exp \left[-\left(\frac{L}{\delta_{c}}\right)^{m+1}\right]-\exp \left[-\frac{L}{L_{0}}\left(\frac{T}{S_{0}}\right)^{m}\right]\right\} .
$$

The last two terms in eqn (20) give the contribution from fiber pull-out, which consists of two parts. The first part corresponds to the case when the recovery length $L_{R}$ is smaller than the composite length $L$. The second part corresponds to the case when the recovery length is greater than the composite length.

The external stress is now explicitly dependent upon the total length of the composite, $L$. By the same method previously used, the stress level at the ultimate is obtained by solving the following equation

$$
1-m \frac{L}{\delta_{c}}\left(\frac{S_{u}}{S_{c}}\right)^{m}+\frac{m}{2}\left(\frac{L}{\delta_{c}}\right)^{2}\left(\frac{S_{u}}{S_{c}}\right)^{m-1}=0
$$

Contrary to the length-independent regime, a closed-form solution does not exist. A typical result for the variation of strength with length is plotted in Fig. 3.

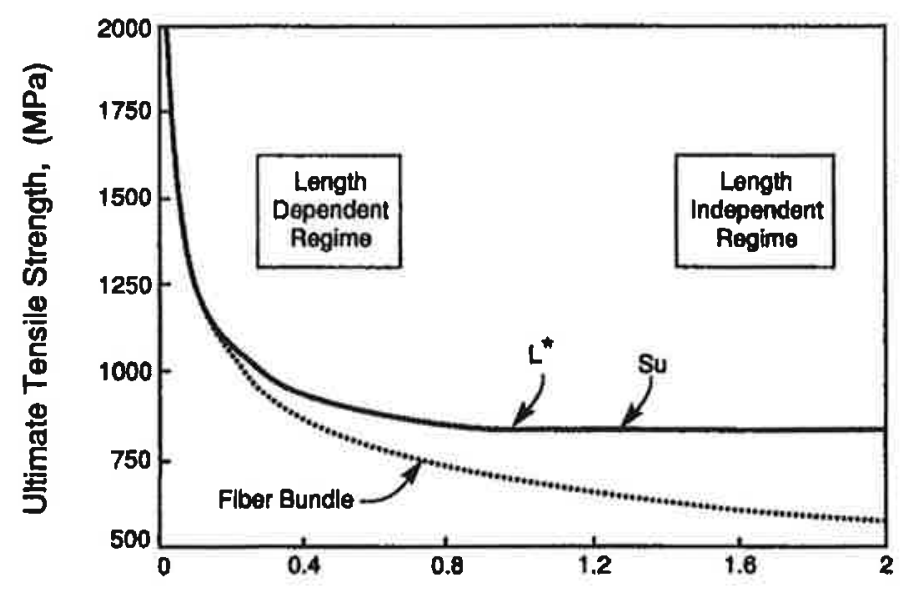

Normalized Composite Length, $L / \delta_{c}$

Fig. 3. Ultimate tensile strength as a function of the normalized total length of the composite. A comparison is made with a fiber bundle prediction. The calculations are based on parameters for SiC/LAS composites (Table I). 


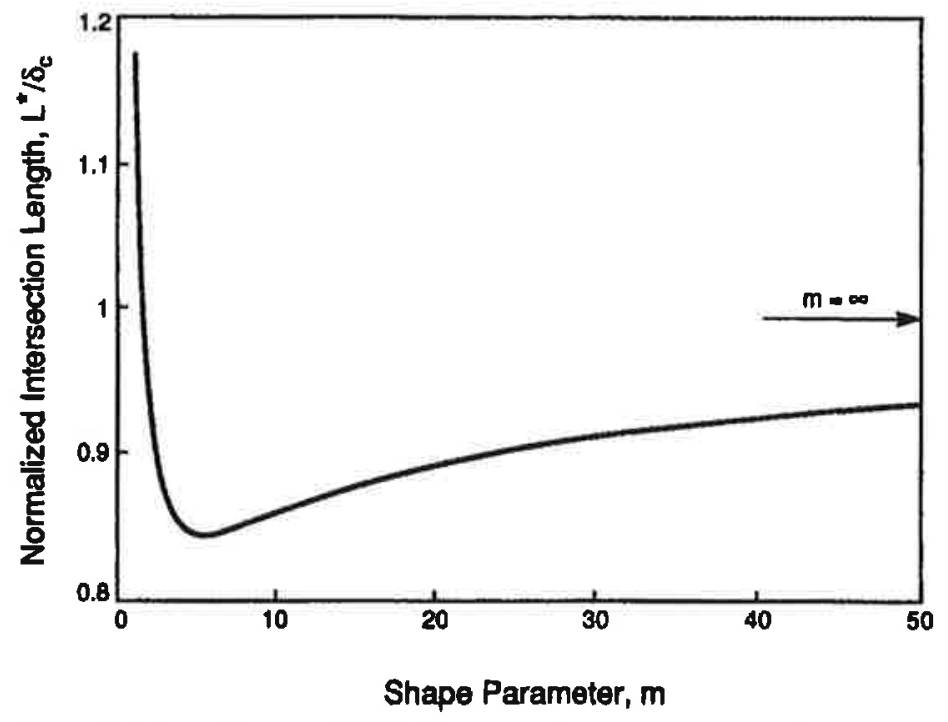

Fig. 4. The intersection length $L^{*}$ between short and long gage length specimens.

A useful approximation for very small $L$ may be obtained by noting that, as $L \rightarrow 0$

$$
S_{u}(L) \approx f S_{0}\left(L_{0} / m L\right)^{1 / m} \exp [-1 / m] \equiv S_{b},
$$

where $S_{b}$ denotes the classical dry bundle strength (Fig. 3). Similar results have been independently derived by Curtin (1992, personal communication).

The solutions for short and long gage lengths intersect in the region where $L / \delta_{c} \approx 1$. The length at the intersection is a transition length, $L^{*}\left(S_{u}\right.$ is length-dependent when $L \leqslant L^{*}$ and length-independent when $\left.L \geqslant L^{*}\right)$. In terms of normalized quantities, the ratio $L^{*} / \delta_{c}$ only depends on $m$ (Fig. 4).

\section{THE FLEXURAL STRENGTH}

Solutions for the ultimate strength in flexure are based on the nonlinear, tensile stressstrain curve for the composite. There are contributions to this strain from matrix cracking and fiber failure. The latter is given by eqn (14). The former depends on various properties of the matrix and the interfaces (Hutchinson and Jensen, 1990; Pryce and Smith, 1992) and varies substantially from one material to another (Evans et al., 1994). For present purposes, a matrix damage parameter is defined that represents the contribution to the inelastic strain from matrix cracking, given by

$$
D=1-E_{s} / \bar{E}
$$

where $E_{s}$ is the secant modulus and $E$ is the elastic modulus of the uncracked composite. A useful approximation, to be used below is

$$
D \approx 1-f E_{f} / \bar{E}
$$

Available results indicate that $D$ can vary between 0 and $\sim 0.8$ (Evans et al., 1994). This difference in the stress-strain law applicable to tension and compression causes a translation of the neutral plane away from the midsection of the beam.

For pure four-point flexure, the strain $\bar{\varepsilon}$ between the inner loading points is related to the curvature $\kappa$ by (Timoshenko and Goodier, 1970) 


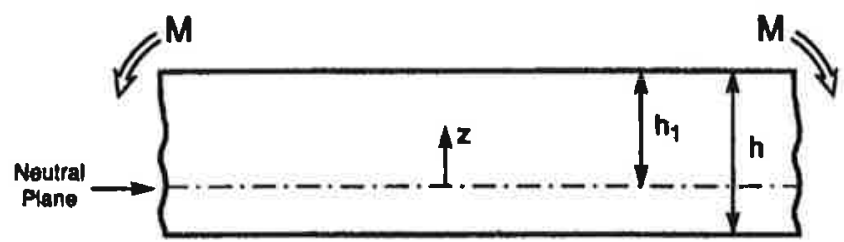

Fig. 5. Definition of the beam geometry in the case of flexure.

$$
\bar{\varepsilon}=\kappa z,
$$

where $z$ is the height coordinate measured from the neutral plane (Fig. 5). On the assumption that global load sharing takes place independently in each plane $z=$ constant, the stress on the tensile side of the neutral plane is obtained from eqn (14b) as

$$
\Sigma=Z\left[1+\sum_{n \geqslant 1} \frac{(-1)^{n}}{2 n !} \frac{2+n(m+1)}{1+n(m+1)} Z^{n(m+1)}\right]
$$

where

$$
Z=E_{f} k z / S_{c}, \quad \Sigma=\bar{\sigma} / f S_{c} .
$$

Force balance dictates the position of the neutral axis, $h_{1}$ (Fig. 5), relative to the beam thickness, $h$. From eqn (27)

$$
h_{1} / h=\left[1+\sqrt{\frac{g(m)}{1-D}}\right]^{-1}
$$

where

$$
g(m)=1+\sum_{n \geqslant 1} \frac{(-1)^{n}}{n !}\left[\frac{1}{1+n(m+1)}\right][2 /(m+1)]^{n} .
$$

When the inner span of the flexural beam $L_{s}$ is sufficiently large so that $L_{s}>L_{\mathcal{K}}$, composite failure in four-point flexure is expected to occur when the stress on the tensile surface reaches the ultimate tensile strength (UTS) given by eqns (3) and (18). $\dagger$ Imposing this failure criterion, the flexural strength $S_{F}$ becomes

$$
S_{F}=f S_{c} H(m, D),
$$

where

$$
H(m, D)=2\left(h_{1} / h\right)^{2}[2 /(m+1)]^{1 /(m+1)}\left[\frac{\left(h / h_{1}-1\right)^{3}}{1-D}+G(m)\right]
$$

and

$$
G(m)=1+3 \sum_{n \geqslant 1} \frac{(-1)^{n}}{n !} \frac{2+n(m+1)}{[1+n(m+1)][3+n(m+1)]}\left[\frac{2^{n-1}}{(m+1)^{n}}\right]
$$

The flexural strength again scales with the characteristic strength, $S_{c}$, and the fiber valid.

†For short flexural specimens, shear failure is more likely than tensile failure and the analysis would not be 


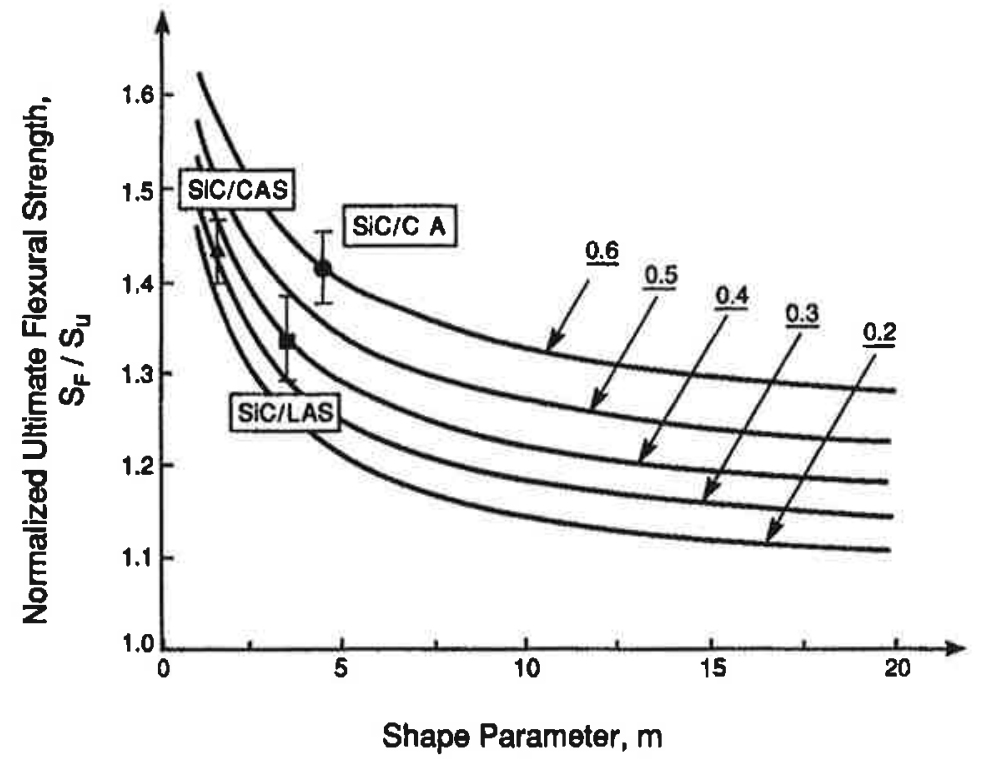

Fig. 6. Normalized flexural strength as a function of Weibull modulus $m$, for different values of the damage parameter $D$. Also shown are experimental values. The associated estimates of $D$ for these materials are given in Table 2.

volume fraction $f$. It is also explicitly dependent upon the matrix damage variable, $D$, and the shape parameter, $m$ (Fig. 6). As $m \rightarrow \infty$, the ratio of the flexural strength to the ultimate tensile strength only depends upon the secant modulus difference between tension and compression: $2 /(1+\sqrt{1-D})$. However, for small $m$, corresponding to greater scatter in fiber failure strength, the normalized flexural strength, $S_{F} / S_{u}$, is increased. Furthermore, the larger the matrix damage variable, $D$, the larger the normalized flexural strength.

\section{COMPARISON WITH EXPERIMENT}

Experimental results in tension and four-point flexure obtained on three different CMCs are summarized in Tables 1 and 2 (Schwartz et al., 1991; Heredia et al., 1992;

Table 1. Summary of tensile data for Nicalon fiber-reinforced CMCs $(R=7.5 \mu \mathrm{m})$

\begin{tabular}{|c|c|c|c|c|c|c|c|}
\hline \multirow[b]{2}{*}{ Matrix material } & \multirow[b]{2}{*}{$f$} & \multirow[b]{2}{*}{$m$} & \multirow[b]{2}{*}{$S_{\mathrm{c}}(\mathrm{GPa})$} & \multirow[b]{2}{*}{$\tau(\mathrm{MPa})$} & \multirow[b]{2}{*}{$L^{*}(\mathrm{~mm})$} & \multicolumn{2}{|c|}{$S_{u}(\mathrm{MPa})$} \\
\hline & & & & & & Measured & Predicted \\
\hline $\begin{array}{l}\mathrm{SiC} / \text { LAS } \\
\text { (Jansson and Lockie, 1992) }\end{array}$ & 0.5 & $3.5 \pm 0.5$ & $2.5 \pm 0.2$ & $5 \pm 0.5$ & $6.5 \pm 1$ & $790 \pm 40$ & 850 \\
\hline $\begin{array}{l}\text { SiC/C A } \\
\text { (Heredia et al., 1992) }\end{array}$ & 0.22 & $4.5 \pm 0.5$ & $2.2 \pm 0.2$ & $12 \pm 2$ & $1.3 \pm 0.2$ & $320 \pm 30$ & 330 \\
\hline $\begin{array}{l}\text { SiC/CAS } \\
\text { (Beyerle et al., 1992) }\end{array}$ & 0.37 & $1.8 \pm 0.5 \dagger$ & $2.0 \pm 0.2$ & $15 \pm 3$ & $0.9 \pm 0.2$ & $430 \pm 30$ & 430 \\
\hline
\end{tabular}

† Correction from J. Am. Ceram. Soc. 76, 560 (1993).

Table 2. Flexural experiments and predictions for CMCs reinforced with Nicalon fibers

\begin{tabular}{lccc}
\hline \multirow{2}{*}{$\begin{array}{c}\text { Matrix } \\
\text { material }\end{array}$} & \multicolumn{2}{c}{$S_{F}(\mathrm{MPa})$} & Damage \\
\cline { 2 - 3 } & Expriment & Prediction & $\begin{array}{c}\text { Dameter } D \dagger \\
\text { paramete }\end{array}$ \\
\hline SiC/LAS & $1050 \pm 50$ & 1110 & 0.38 \\
$\mathrm{SiC} / \mathrm{CA}$ & $430 \pm 50 \ddagger$ & 420 & 0.30 \\
$\mathrm{SiC} / \mathrm{CAS}$ & $620 \pm 30$ & 645 & 0.45 \\
\hline
\end{tabular}

$\dagger D \approx 1-f E_{f} / E$.

† From Schwartz et al. (1991). 


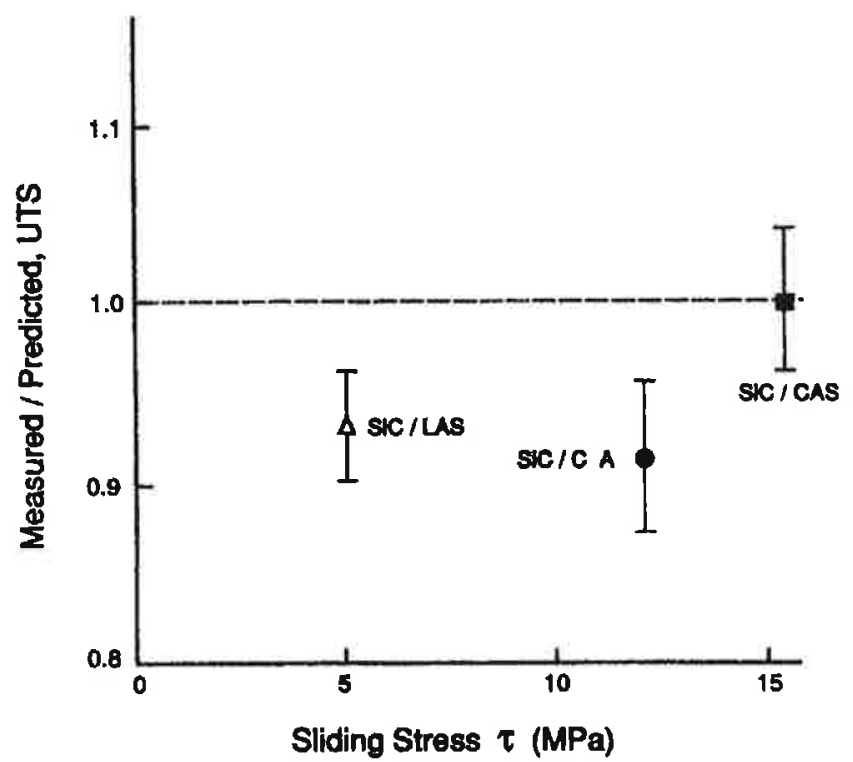

Fig. 7. Comparison of predicted and measured UTS for three different CMCs.

Beyerle et al., 1992 ; Jansson and Leckie, 1992). Based on the parameters indicated in Table 1 , it is apparent that all of the tensile data refer to the long gage length regime. Consequently, eqns (3) and (18) may be used to predict the UTS. A comparison with experiment is indicated on Fig. 7, using $\tau$ as a convenient plotting variable. The correspondence is quite good. Consequently, eqn (18) appears to provide a useful expression for $F(m)$, further justifying the use of this analytical approximation. Departure from the predictions reflects uncertainties in the parameters, as well as minor deviations from global load sharing.

The flexural results (Table 2) are also in the gage length independent regime. The normalized ultimate flexural strength, plotted on Fig. 6, generally support the predictions with the greatest discrepancy being $11 \%$ for the $\mathrm{SiC} / \mathrm{C}$. $†$ Further, detailed comparisons between experiment and theory await additional information about $D$ for each of the three materials.

\section{CONCLUDING REMARKS}

A lower bound of the ultimate strength in tension and flexure has been derived within the framework of global load sharing, in terms of the two main characterizing parameters, $\delta_{c}$ and $S_{c}$. A characteristic length, $\delta_{c}$, provides a dimension that differentiates long and short specimens and establishes two different regimes: a length-dependent ultimate strength for short specimens $\left(L \leqslant \delta_{c}\right)$ and a length-independent ultimate strength for long specimens $\left(L \geqslant \delta_{c}\right)$. The characteristic strength, $S_{c}$, allows scaling of the ultimate tensile strength and flexural strength, provided that the specimens are long. In flexure, there is also an important influence of matrix cracking, which affects the ratio of the tensile-to-compressive secant modulus. Both experiment and theory suggest that the flexural strength is substantially larger than the tensile strength.

Acknowledgements-This work was supported by the Defense Advanced Research Projects Agency through the University Research Initiative under Office of Naval Research Contract No. N-00014-92-J-1808 and the Air Force Office of Scientific Research under Grant 90-0132.

†In the CAS matrix material, premature failure occurred due to shear, which would cause the experimental value to be lower than predicted. 


\section{REFERENCES}

Aveston, J., Cooper, G. A. and Kelly, A. (1971). Single and multiple fracture. In The Properties of Fiber Composites, pp. 15-26. IPC.

Beyerle, D. S., Spearing, S. M., Zok, F. W. and Evans, A. G. (1992). Damage, degradation and failure in a unidirectional ceramic-matrix composite. J. Am. Ceram. Soc. 75, 2719-2725.

Cao, H. C., Bischoff, E., Sbaizero, O., Rühle, M. and Evans, A. G. (1990a). Effect of interfaces on the properties of fiber-reinforced ceramics. J. Am. Ceram. Soc. 73, 1691-1699.

Cao, H. C. and Thouless, M. D. (1990b). Tensile tests of ceramic-matrix composites : theory and experiment. J. Am. Ceram. Soc. 73, 2091-2094.

Cox, H. L. (1952). The elasticity and the strength of paper and other fibrous materials. Br. J. Appl. Phys. 3, 7279.

Curtin, W. A. (199/a). Exact theory of fiber fragmentation in single-filament composite. J. Mat. Sci. 26, 52395253.

Curtin, W. A. (1991b). Theory of mechanical properties of ceramic matrix composites. J. Am. Ceram. Soc. 74 2837-2845.

Evans, A. G., Domergue, J.-M. and Vagaggini, E. (1994). A methodology for relating the tensile constitutive behavior of ceramic matrix composites to constituent properties. J. Am. Ceram. Soc., to be published.

Henstenburg, R. B. and Phoenix, S. L. (1989). Interfacial shear strength using single-filament-composite test. Part II : a probability model and Monte Carlo simulations. Polymer Comp. 10, 389-406.

Heredia, F. E., Spearing, S. M., Evans, A. G., Mosher, P. and Curtin, W. A. (1992). Mechanical properties of carbon matrix composites reinforced with Nicalon fibers. J. Am. Ceram. Soc. 75, 3017-3025.

Hild, F, Larsson, P.-L. and Leckie, F. (1992), Localization due to damage in fiber reinforced composites. Int. $J$. Solids Structures 29, 3221-3238.

Hult, J. and Travnicek, L. (1983). Carrying capacity of fiber bundles with varying strength and stiffness. $J$. Mécanique Théorique el Appliquée 2, 643-657.

Hutchinson, J. W. and Jensen, M. (1990). Models of fiber debonding and pull-out in brittle composites with friction Mech. Mater. 9, 139-163.

Jansson, S. and Leckie, F. A. (1992). The mechanics of failure of silicon carbide fiber-reinforced glass-matrix composites. Acta Metall. 40, 2967-2978.

Kachanov, L. M. (1958). Time of the rupture process under creep conditions. Izv. Akad. Nauk. S.S.R. Odt. Tekh. Nauk. 8, 26-31.

Kelly, A. (1973). Strong Solids, Chap. 5, 2nd edn, Oxford University Press.

Krajcinovic, D. and Silva, M. A. G. (1982). Statistical aspects of the continuous damage theory. Int. J. Solids Structures 18, 55!-562.

Lemaitre, J. and Chaboche, J.-L. (1985). Mécanique des Matériaux Solides, Dunod, Paris ; English translation, 1990. Mechanics of Solid Materials, Cambridge University Press, Cambridge.

Phoenix, S. L. (1993). Statistical issues in the fracture of brittle matrix fibrous composites. Comp. Sci. Technol. 48, 65-80.

Pryce, A. W. and Smith, P. A. (1992). Modelling the stress/strain behaviour of unidirectional ceramic matrix composite laminates. J. Mater. Sci. 27, 2695-2704.

Rabotnov, Y. N. (1963). On the equations of state for creep. In Progress in Applied Mechanics, Prager Anniversary Volume. Macmillan, New York.

Schwartz, S., Lee, S. and Mosher, P. (1991). Properties of silicon carbide fiber reinforced carbon composite. 15th Annual Conference on Composite Materials and Structures, $A C e r S$, Cocoa Beach, FL.

Timoshenko, S. P. and Goddier, J. N. (1970). Theory of Elasticity, 3rd edn. McGraw-Hill.

Weibull, W. (1939). A statistical theory of the strength of materials. Ingeniörsvetenskapakademiens, Handlingar No. 151

\section{APPENDIX: ESTIMATION OF PULL-OUT STRESS}

When only the broken fibers inside the recovery length are considered, the expression for the pull-out stress is simply

$$
\sigma_{p}(T)=\int_{0}^{T} \frac{\sigma}{2} \frac{\mathrm{d} P_{F}}{\mathrm{~d} \sigma} \mathrm{d} \sigma .
$$

However, when the fiber breaks which originally occurred outside the recovery length and are then brought in are considered, $\nmid$ but the exclusion zones are neglected, the pull-out stress has been estimated by Curtin (1991) as

$$
\sigma_{p}(T)=\frac{T}{2} P_{F}(T)
$$

Since $\sigma \leqslant T$

$$
\int_{0}^{T} \frac{\sigma}{2} \frac{\mathrm{d} P_{F}}{\mathrm{~d} \sigma} \mathrm{d} \sigma<\frac{T}{2} P_{r}(T) .
$$

Consequently, eqn (A1) represents a lower bound for $\sigma_{\rho}(T)$. The average pull-out stress, given by eqn (A1) with $P_{F}(\sigma)$ given in eqn $(8)$ is

† The recovery length increases in proportion to $T$. 


$$
\sigma_{p}(T)=\frac{S_{c}}{2} \gamma\left[\frac{m+2}{m+1} ;\left(\frac{T}{S_{c}}\right)^{m+1}\right],
$$

where $\gamma[\cdot ; \cdot]$ represents the incomplete gamma function. In order to make a direct comparison of the influence of the exclusion zones and the recovery length on the UTS, these two values of $\sigma_{p}$, plus a third value derived by Phoenix (1993) are used. Moreover, the comparison is made by adopting the same choice for $T$, at the UTS, given by eqn (16). + The lower bound UTS based on eqn (A4) is given by eqn (18). The result based on eqn (A2) is

$$
\begin{aligned}
S_{\mathrm{N}} & =\frac{f T}{2}\left[1+\exp \left(-\left(\frac{T}{S_{c}}\right)^{m+1}\right)\right] \\
& \equiv \frac{f S_{c}}{2}\left(\frac{2}{m+1}\right)^{1 /(m+1)}\left[1+\exp \left(-\frac{2}{m+1}\right)\right] .
\end{aligned}
$$

The rigorous result is (Phoenix, 1993)

$$
\begin{aligned}
S_{u} & =\frac{f T}{2}\left[1+\exp \left(-\{(m+1) / m\}\left[1-\exp \left(\{m /(m+1)\}\left(\frac{T}{S_{c}}\right)^{m+1}\right)\right]\right)\right] \\
& \equiv \frac{f S_{c}}{2}\left(\frac{2}{m+1}\right)^{1 / m+1}\left[1+\exp \left(-\{(m+1) / m\}\left[1-\exp \left(\{m /(m+1)\}\left(\frac{2}{m+1}\right)\right)\right]\right)\right] .
\end{aligned}
$$

These three results are plotted in Fig. 2.

† Note that Curtin's numerical estimate of $T$ at the UTS differs from eqn (16), leading to yet another prediction of the UTS, which is not explicitly considered in the present comparison. 